\title{
Pathological and Clinical Basis of the Indications for Treatment of Craniopharyngiomas
}

\author{
Tatsuya Kobayashi, Naoki Kageyama, Jun Yoshida, \\ Naoki SHIBUYA and Takeshi YonEZAWA* \\ Department of Neurosurgery, Nagoya University \\ School of Medicine, Nagoya 466 \\ * Department of Pathology, Kyoto Prefectural \\ University of Medicine
}

\begin{abstract}
Summary
Pathological and clinical studies were performed concerning the indications of operative treatment for craniopharyngiomas with seven autopsied brains and 15 cases which had been treated by extensive removal of the tumor.

From the present study, it could be concluded that the total removal of the tumor was not always possible without potential neuroendocrinological deficits. The pathological basis is that the tumor cells invaded adjacent brain structures as fingershaped or island-like protrusions without significant glial cleavage and with close approximation to the neurons of the micron order in some cases, while in the other cases, a thicker layer of gliosis including Rosenthal fibers and fibrillary astrocytes existed between the tumor and neuronal structures.

From the clinical study, the risk factors in the indication of extensive removal of craniopharyngioma could be correlated with the prognosis. These factors are the size and the location of the tumor, the existence of diabetes insipidus and psychiatric signs, and more significantly an irregular defect in the floor of the third ventricle.
\end{abstract}

Key words: Craniopharyngioma, autopsy, glial cleavage, radical surgery, irradiation, combined therapy

\section{Introduction}

There has been some controversy regarding the treatment of craniopharyngioma. Surgical extirpation of the tumor has long been considered as the ideal choice of treatment because of its biopathological nature. ${ }^{7,9,10,15,23 \text {, }}$ However, there is a dilemma for the neurosurgeon between "total" removal and severe neuroendocrinological complications. It is also known that recurrence of the tumor was often reported after "total" removal. ${ }^{10 \text { ) }}$

On the other hand, radiation therapy using external or internal irradiation, has been recognized to have definite static effects on the tumor in many cases. ${ }^{1,3,6,11,12,17)}$

Consequently, a combination of both treatments is currently in use and a better prognosis has been obtained. ${ }^{2,4,8,14,21)}$
In this paper, we discuss the possibility of surgical extirpation of craniopharyngioma based on the pathological findings of autopsied brains and clinical observations of cases in which extensive removal was performed.

\section{Materials and Methods}

Autopsy study: Seven autopsied brains were examined in the study. Four of these were obtained from the Department of Pathology, Nagoya University School of Medicine and Department of Pathology, Kyoto Prefectural University of Medicine. They had a clinical diagnosis of craniopharyngioma and were confirmed by autopsy without direct surgery on the tumor. Three other cases were obtained from our Department and died without major surgery on the tumor. Macroscopic observations of the coronal and mid-sagittal sections 
including the tumor were performed in each case. The size and nature as well as the localization of the tumor were examined on three dimensional planes. Special attention was paid to the study of the microscopic relationship between the tumor and adjacent brain tissues such as the hypothalamus, basal ganglia or optic pathways using serial sections, with H-E, PTAH, Klüver-Barrera, Nissl and/or Masson Trichrom stains.

Clinical study: Fifteen cases of craniopharyngioma were subjected to the present study. Five of them were considered as "total" removal, and ten underwent "subtotal" removal. Nine out of the latter cases were irradiated after removal. Clinical evaluation of the efficacy of this extensive surgery was performed in correlation with the preoperative clinical signs and neuroradiological findings. The localization, the size of the tumor and the defect of the third ventricle were reconstructed on tracing paper from the carotid angiographic findings, $\mathrm{PE}(\mathrm{V}) \mathrm{G}$ or computed tomography. The tumor size was expressed as its volume, calculated by the formula: Volume $=d_{1} \times d_{2} \times d_{3} \times 1 / 2$, where $d_{1}$, $\mathrm{d}_{2}, \mathrm{~d}_{3}$ indicate three dimensional diameters of a tumor in a reconstructed figure or CT scans. The irregularity of the defect of the third ventricle was traced from the ventriculographic findings. Preoperative neurological signs and symptoms, especially the exsistence of diabetes insipidus, signs of increased intracranial pressure and psychiatric signs, were checked in each case.

\section{Results}

Autopsy study: The seven cases are summarized in Table 1 with regard to the nature, localization and size of the tumor, and are illustrated in Fig. 1. The tumor was mainly cystic in five cases, two of which were multicystic and mixed with a solid portion. Two were mainly solid tumors. The volume of the tumor was varied from a minimum of $2.0 \mathrm{ml}$ to a maximum of $50.0 \mathrm{ml}$. The larger size (more than $30 \mathrm{ml}$ ) was found in two, the medium size $(10-30 \mathrm{ml})$ in two and the smaller size (less than $10 \mathrm{ml}$ ) in three cases. Regarding the location of the tumors, the larger tumors had extended into the third ventricle upwards and/or had invaded the bilateral thalamus posteriorly, while the smaller tumors remained in the retrochiasmal region.

From microscopic examinations on the relationship between cystic tumors and their adjacent neural tissues, it was found that the cyst walls were composed of a tumor cell layer inside and a connective tissue membrane outside. The tumor cell layer had a variable

Table 1 Summary of autopsy cases with craniopharyngioma.

\begin{tabular}{|c|c|c|c|c|c|c|c|c|}
\hline $\begin{array}{l}\text { Case \# } \\
\text { Age }\end{array}$ & Sex & Signs \& symptoms & Location & Treatment & $\begin{array}{l}\text { Onset to } \\
\text { death }\end{array}$ & $\begin{array}{c}\text { Cause of } \\
\text { death }\end{array}$ & Nature & Size $(\mathrm{cm})$ \\
\hline 1. N.K. ${ }^{\circ} 6$ & $\mathrm{~F}$ & $\begin{array}{l}\text { anorexia, nausea, vomiting, } \\
\text { dwarfism, visual dist. }\end{array}$ & retrochiasm. & $\begin{array}{l}\text { craniotomy } \\
\text { (cyst drain.) }\end{array}$ & $1 \mathrm{y} 1 \mathrm{~m}$ & epilepsy & cystic & $\begin{array}{l}\text { small } \\
2 \times 2 \times 1\end{array}$ \\
\hline 2. K.T. ${ }^{\circ} 13$ & $\mathbf{M}$ & $\begin{array}{l}\text { visual dist., dwarfism, } \\
\text { headache, vomiting, } \\
\text { drowsiness }\end{array}$ & $\begin{array}{l}\text { third vent. } \\
\text { thalamus }\end{array}$ & $\begin{array}{l}\text { ventricular } \\
\text { drainage }\end{array}$ & $2 \mathrm{y} 7 \mathrm{~m}$ & $\begin{array}{l}\text { hypothalamic } \\
\text { dysfunction }\end{array}$ & $\begin{array}{l}\text { multicyst } \\
+ \text { solid }\end{array}$ & $\begin{array}{l}\text { large } \\
5 \times 4 \times 4\end{array}$ \\
\hline 3. K.M.'19 & $\mathbf{M}$ & $\begin{array}{l}\text { nausea, vomiting, diplopia, } \\
\text { obesity, delusion, } \\
\text { drowsiness }\end{array}$ & $\begin{array}{l}\text { third vent. } \\
\text { thalamus }\end{array}$ & $\begin{array}{l}\text { ventricular } \\
\text { drainage }\end{array}$ & $10 \mathrm{y}$ & pneumonia & $\begin{array}{l}\text { multicyst } \\
+ \text { solid }\end{array}$ & $\begin{array}{l}\text { large } \\
5 \times 5 \times 4\end{array}$ \\
\hline 4. R.M. 20 & $\mathrm{~F}$ & $\begin{array}{l}\text { visual dist., obesity, } \\
\text { psychiatric signs }\end{array}$ & retrochiasm. & $\begin{array}{l}\text { craniotomy } \\
\text { (biopsy) }\end{array}$ & $4 y$ & pneumonia & cystic & $\begin{array}{l}\text { small } \\
2 \times 2 \times 2\end{array}$ \\
\hline 5. M.F."31 & M & $\begin{array}{l}\text { visual dist., drowsiness, } \\
\text { diabetes insipidus }\end{array}$ & retrochiasm. & none & $1 y 6 \mathrm{~m}$ & $\begin{array}{l}\text { hypothalamic } \\
\text { dysfunction }\end{array}$ & cystic & $\begin{array}{l}\text { small } \\
3 \times 2 \times 2\end{array}$ \\
\hline 6. K.T. 40 & $\mathrm{~F}$ & $\begin{array}{c}\text { amenorrhea, galactorrhea, } \\
\text { obesity, mental change }\end{array}$ & third vent. & $\begin{array}{l}\text { craniotomy } \\
\text { (biopsy) }\end{array}$ & $\operatorname{ly} 2 \mathrm{~m}$ & colitis & solid & $\begin{array}{l}\text { medium } \\
3.5 \times 3 \times 2\end{array}$ \\
\hline 7. T.S." 43 & $\mathbf{M}$ & $\begin{array}{l}\text { visual dist., headache, } \\
\text { vomiting, mental } \\
\text { change }\end{array}$ & third vent. & none & $2 y$ & $\begin{array}{l}\text { hypothalamic } \\
\text { dysfunction }\end{array}$ & solid & $\begin{array}{l}\text { medium } \\
4 \times 4 \times 3\end{array}$ \\
\hline
\end{tabular}

third vent.: tumor extension into third ventricle. thalamus: tumor invasion into thalamus. "cases from Department of Neurosurg. Nagoya Univ. "cases from Department of Pathology, Nagoya Univ. 'cases from Dept. of Pathology, Kyoto Pref. Univ. of Med. 

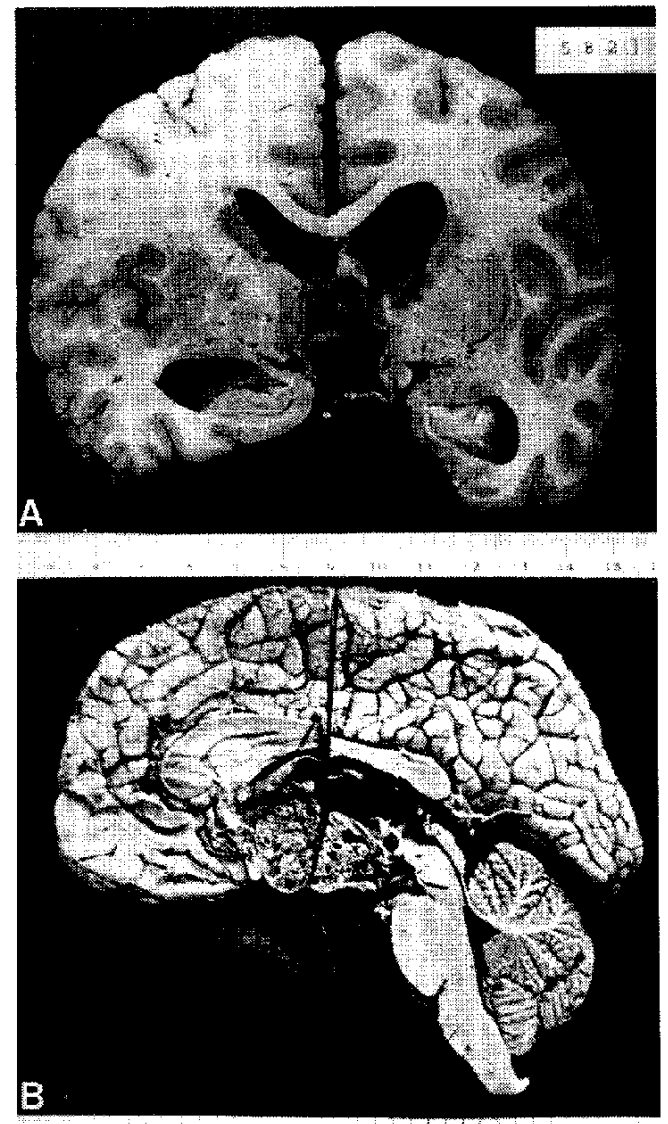

Fig. 1 A: Coronal section of Case 5 .

A small cystic tumor $(3 \times 3 \times 2 \mathrm{~cm})$ is located in the retrochiasmal region and the third ventricle is elevated.

B: Sagittal section of Case 7.

A solid tumor with small cysts $(4 \times 4 \times 3 \mathrm{~cm})$ occupies the third ventricle and shows posterior extension into the mammillary body.

width from a single cell to a stratified arrangement of tumor cells. The thickness of the connective tissue membrane was also variable depending upon the size of the cyst. This capsule was attached smoothly to the adjacent brain tissue with or without pial membrane. A distinct layer of gliosis was found between the cyst wall and viable ganglion cells in the thalamus or hypothalamus, the width of which ranged from several hundred microns to a few millimeters. The neuronal degeneration and demyelination of the fibers in this layer were confirmed by Nissl and myelin stains, and they were found to be replaced by abundant Rosenthal fibers and fibrillary astrocytes (Fig. 2).

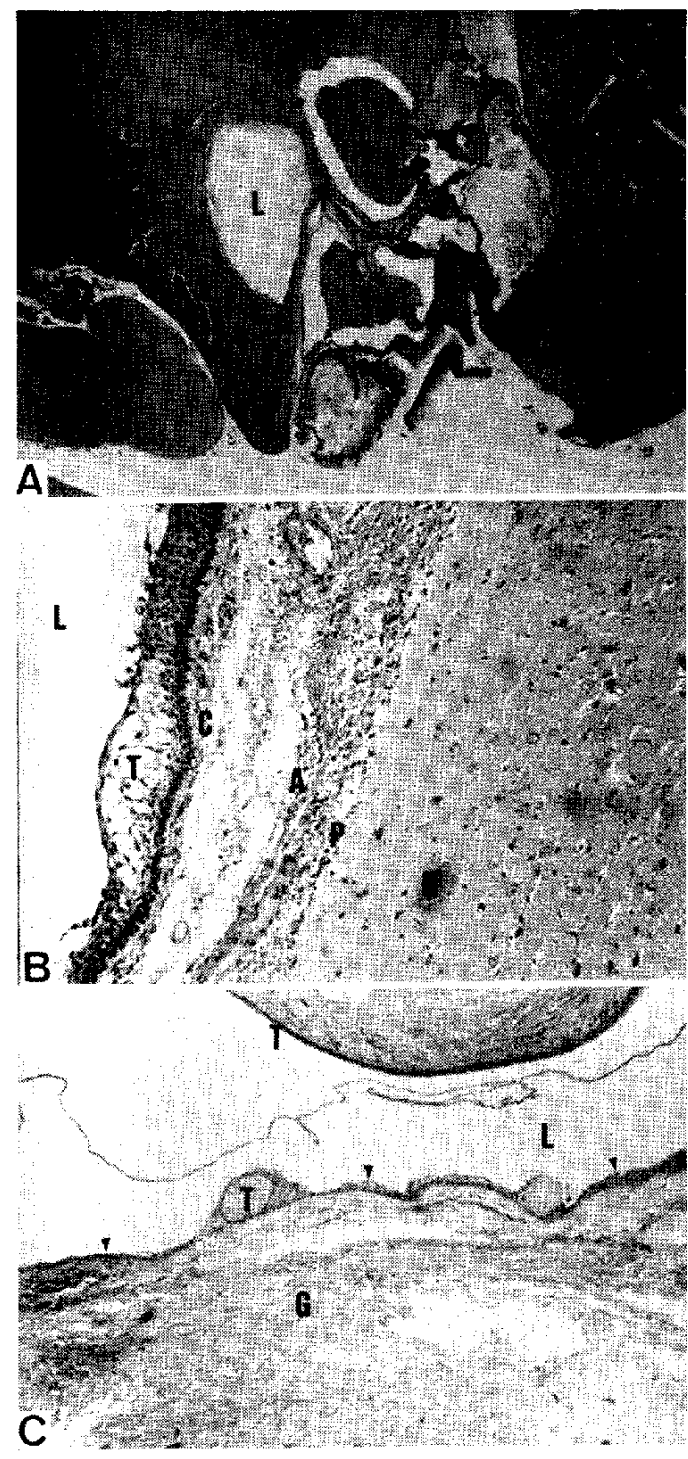

Fig. 2 A: Macroscopic findings of Case $2 . \times 1.5$, H-E.

A multicystic tumor invading the third ventricle and thalamus. Each cyst has a tumor cell layer (T) facing its cavity (L) and a connective tissue capsule (C) outside.

B: Microscopic findings of Case $1 . \times 200$, Masson Trichrom.

The cyst wall is composed of several layers of tumor cells ( $T$ ) on its luminal side (L) and of a connective tissue layer (C) outside. Arachnoid (A) and pial (P) membranes exist between the capsule and brain. No gliosis is found in the brain.

C: Microscopic findings of Case $5 . \times 100$, PTAH.

The sheet (arrows) of tumor cells (T) is attached to the brain tissue without a connective tissue layer. Abundant gliosis is found between the tumor layer and neurons. 

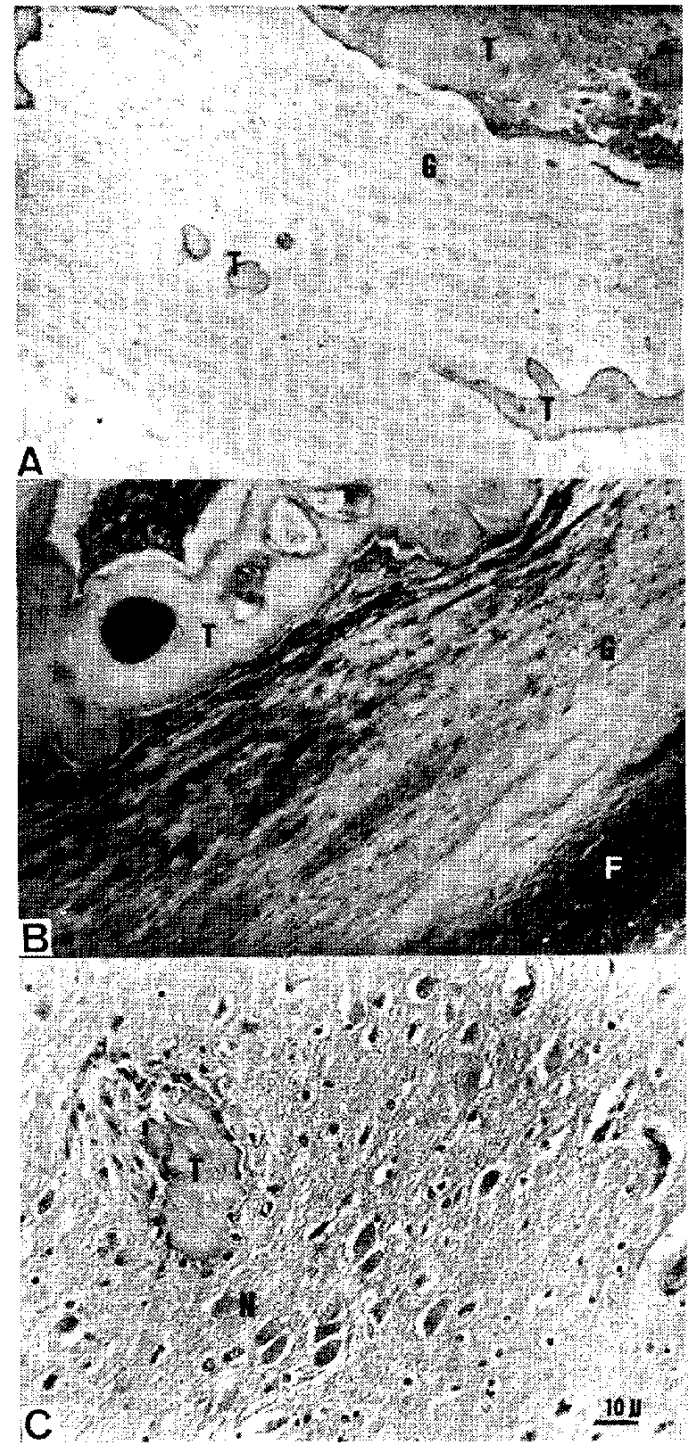

Fig. 3 A: Microscopic findings of Case 7. $\times 100$, H-E.

Finger-shaped and island-like protrusions of tumor cells $(T)$ are found in the adjacent brain tissue. Surrounding gliosis $(G)$ is rich in Rosenthal fibers and fibrillary astrocytes.

B: Microscopic findings of Case $7 . \times 200$, Klüver-Barrera.

A tumor sheet $(\mathrm{T})$ is invading the white matter of the hypothalamus. A thick layer of demyelinated fibers and gliosis $(G)$ is found between the tumor and normal axons $(F)$.

C: Microscopic findings of Case $6 . \times 400$, H-E.

A tumor island $(T)$ is closely approximated to the neurons $(\mathrm{N})$ of the hypothalamic nucleus without glial reactions.
In contrast, the solid tumors or the solid portions of the mixed tumors showed a slightly different pattern in relation to the adjacent brain tissues. The islands or finger-shaped protrusions of tumor cells invaded the adjacent brain without any connective tissue membrane. In some places, a layer of gliosis around the invading islands was found. However in other parts, tumor islands were closely approximated in the order of microns to the viable neurons in the hypothalamus and thalamus without obvious glial reactions (Fig. 3 ).

Clinical study: The clinical features and operative results of the 15 cases with extensive removal of craniopharyngiomas are summarized in Table 2 and typical cases are illustrated in Figs. 4 and 5. Regarding the nature of the tumor, mainly cystic tumors were found in seven, solid tumors in four and mixed cystic and solid tumors in four cases. The volume of the tumor varied from a minimum of $3.0 \mathrm{ml}$ to a maximum of $55.0 \mathrm{ml}$, and the mean size was $24.0 \mathrm{ml}$. Irregular defects in the floor of the third ventricle were found in six cases. The other nine cases had either a smooth or concave defect of the anterior part of the third ventricular floor except for one case with an intrasellar tumor.

Among the clinical signs and symptoms, visual disturbances were found in 13, hypopituitarism in nine, and diabetes insipidus and signs of intracranial hypertension in seven cases preoperatively. Psychiatric signs were found in three cases. The follow-up period of surviving cases ranged from 6 months to 7 years (mean: 42.7 months). Prognosis was excellent in seven, good in two and fair in one. Death occurred in five cases. There were two operative deaths and deaths from tumor recurrence occurred in three cases in the subtotal removal group.

Correlations between these clinical factors and the prognosis are illustrated in Figs. 6 and 7. Among the clinical signs and symptoms, a high correlation was found between the preoperative exsistence of diabetes insipidus or psychiatric signs, and poor prognosis. However, no correlation was found between the age of patients or signs of increased intracranial pressure and the prognosis. From a neuroradiological point of view, the size of the tumor and the nature of the defect of the 


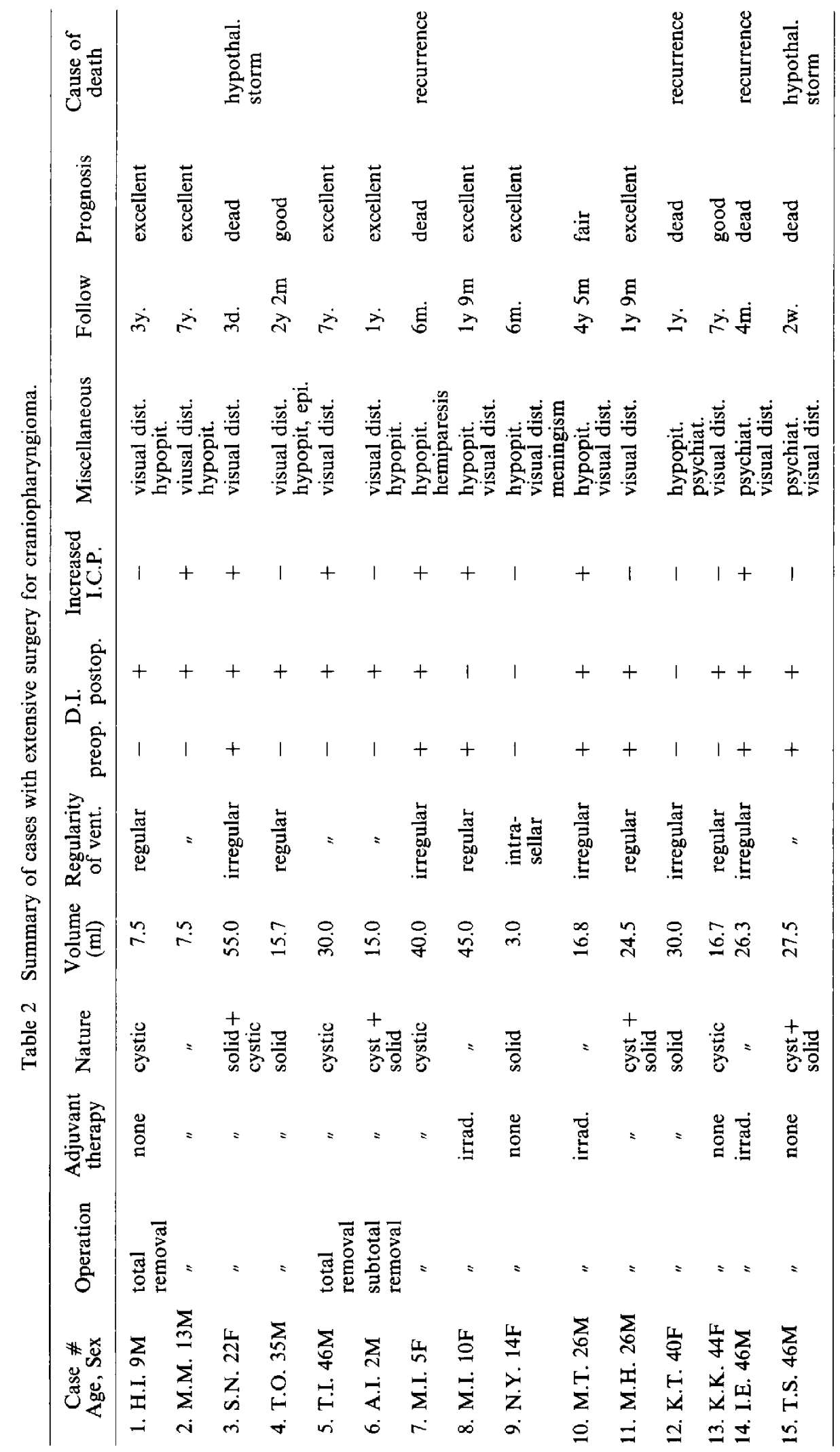



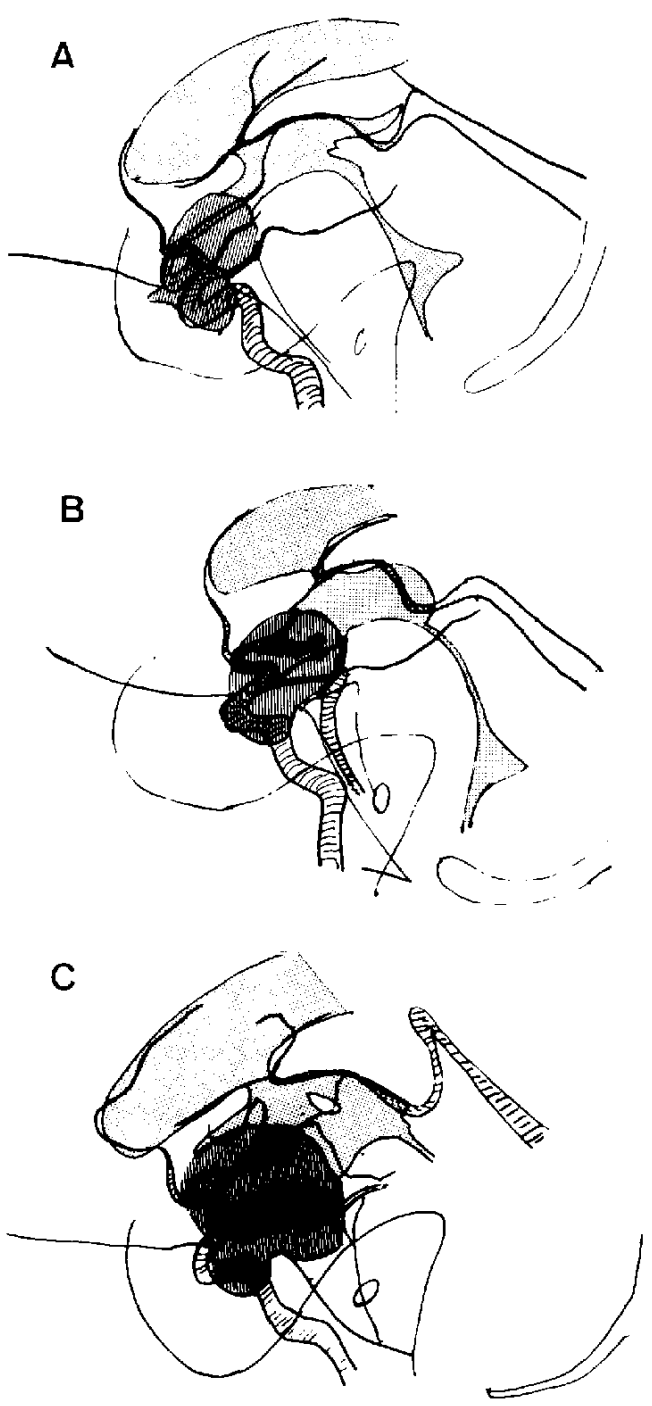

Fig. 4 Reconstructed illustrations of the relationship between the tumor and surrounding brain structures.

A: Case 2- The small $(7.5 \mathrm{ml})$ cystic tumor was totally removed. The smooth defect of the anterior third ventricle by the tumor is shown. Patient is doing well 7 years after the operation.

B: Case 1- Total removal of the small, cystic tumor was performed. A smooth, concave defect of the anterior third ventricle is noted. The patient's prognosis has been excellent for 3 years after the operation.

C: Case 11- The tumor was mainly cystic with a solid part. Subtotal removal of this medium-sized tumor $(24.5 \mathrm{ml})$ followed by irradiation resulted in excellent prognosis.
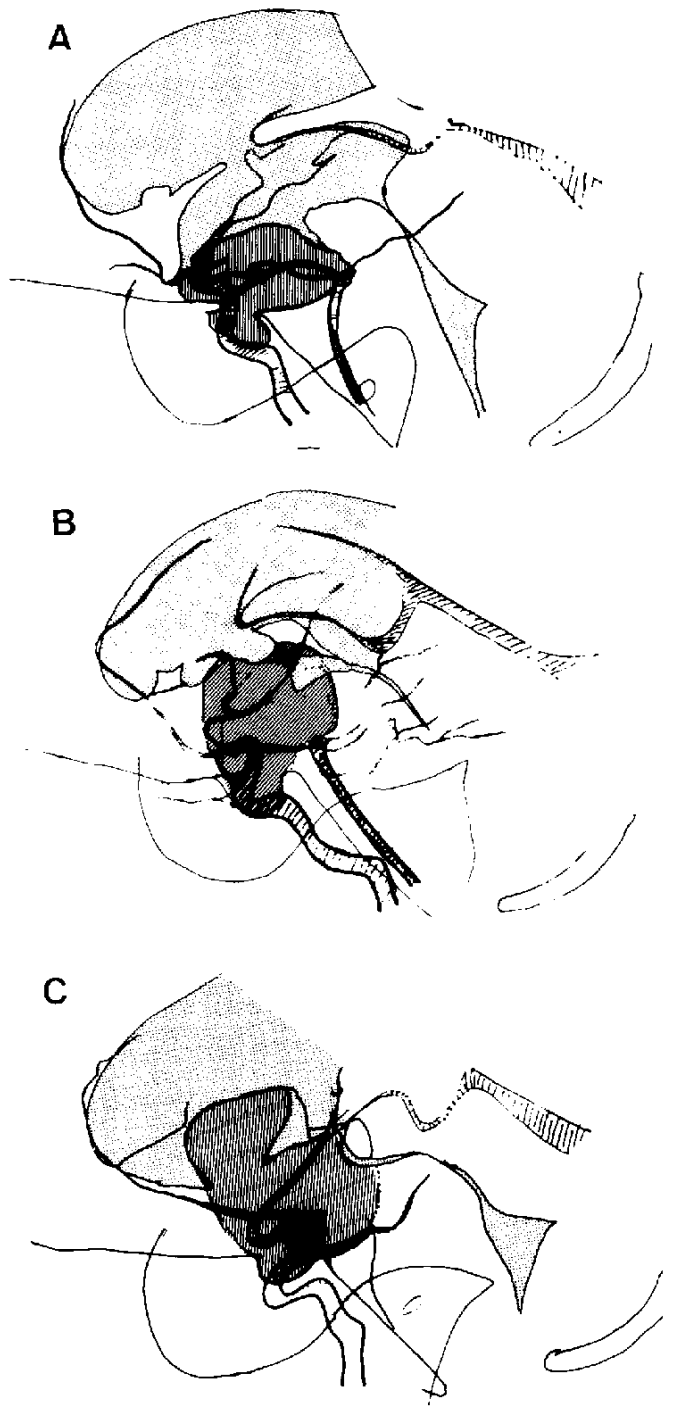

Fig. 5 Reconstructed illustrations of the relationship between tumors and surrounding brain structures.

A: Case 10- This mainly solid tumor, with a volume of $16.8 \mathrm{ml}$, was subtotally removed except for the firm attachment of the tumor to the floor of the third ventricle, and radiation therapy followed. Patient is doing fair after 4 years and 5 months.

B: Case 15- This large tumor $(27.5 \mathrm{ml})$, mixed with cysts and solid portions, was subtotally removed except for the invading part of the tumor into the hypothalamus. Patient died two weeks after the operation without recovery from a hypothalamic storm.

C: Case 3- This large tumor $(55.0 \mathrm{ml})$ was totally removed but the patient died on the 3 rd postoperative day from hypothalamic derangement. 


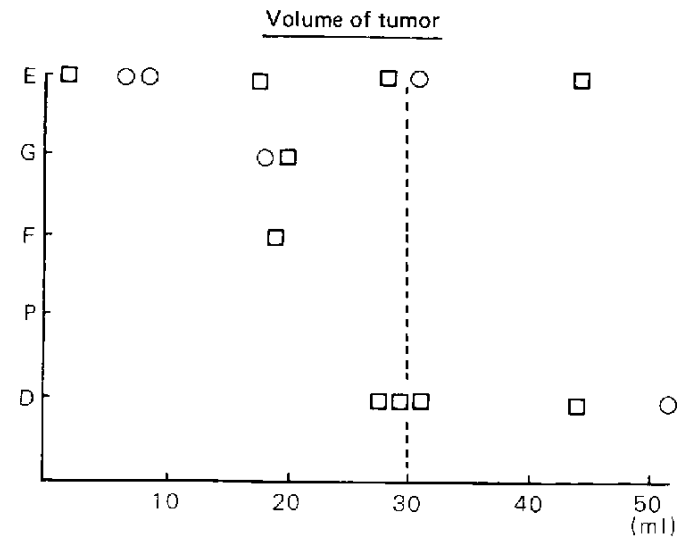

Age of patient

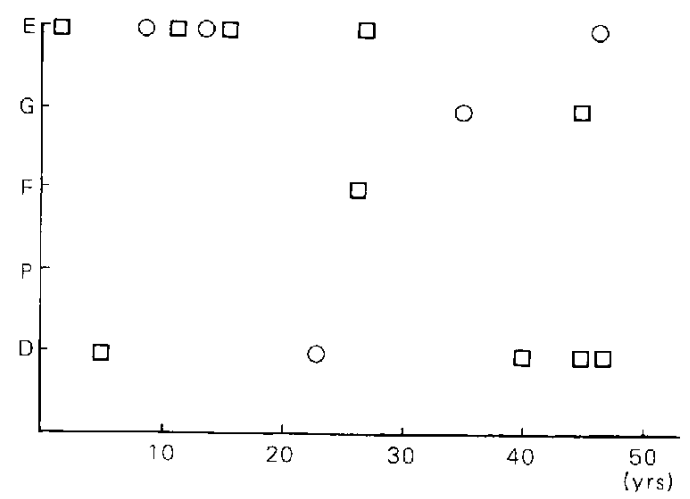

Fig. 6 Correlation between factors and prognosis.

Upper: The volume of tumor is significantly correlated with the prognosis. The greater the volume, the poorer the prognosis. The critical volume is estimated as about $30 \mathrm{ml}$ (dotted line).

Lower: The age of the patient is not correlated with the prognosis. (The circles indicate total and the squares, subtotal removal.)

third ventricular floor were correlated well with the prognosis, i.e. patients with a tumor volume of more than $30.0 \mathrm{ml}$ and/or irregular defects in the floor of the third ventricle showed poor operative results irrespective of the nature of the tumor.

\section{Discussion}

The most important factor influencing the prognosis of total removal of craniopharyngiomas has been considered to be the relationship between the tumor and adjacent vital structures. $^{5,10,18,20)}$ The invading nature of craniopharyngiomas into the brain tissue had been well documented ${ }^{9,19)}$ although the tumors were histologically classified as benign.
D.I.
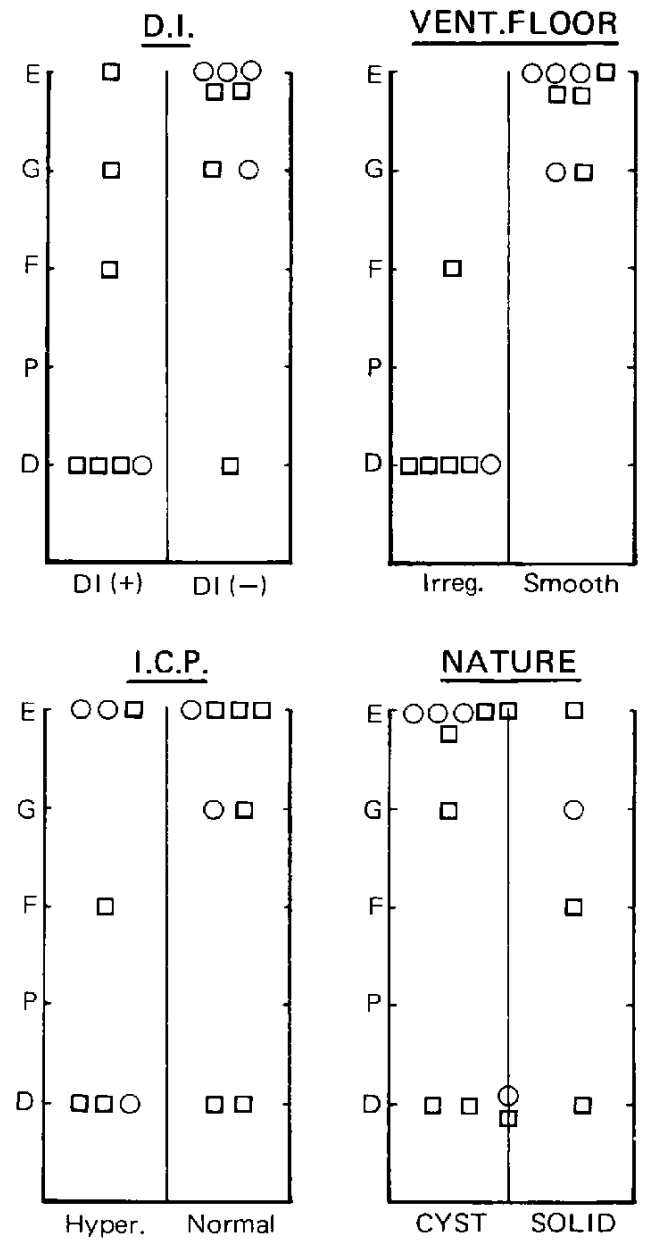

Fig. 7 Correlation between factors and prognosis. The existence of diabetes insipidus (D.I.) and irregular defects in the third ventricular floor (VENT. FLOOR) are well correlated with poor prognosis, while the signs of intracranial hypertension (I.C.P.) and the nature of the tumor (NATURE) are not correlated with the prognosis. (The circles indicate total and the squares, subtotal removal.)

This characteristic is a cause of the difficulty in total removal without severe neurological deficits and recurrences. ${ }^{2,20)}$ The contraindication of total removal in cases with tumor invasion of internal carotid arteries ${ }^{7)}$ or the optic pathway $^{8)}$ has been stressed.

Among the surrounding structures, the hypothalamus is the most critical part for the neurosurgeon. Those who insist on radical operations are of the opinion that a definite cleavage of glial tissue between the tumor and normal neurons exists and that this makes total 
resection of the tumor possible without severe neuronal damage of the hypothalamus. ${ }^{7,23)}$ However, pathological evidence for this concept has long been lacking, and recurrences have often been encountered after "total" removal. Recently Kubota et al. using autopsied brains ${ }^{13)}$ and Sweet using clinical materials ${ }^{23}$ ) have shown that there is such a thick glial cleavage around the tumor. In this study, however, we not infrequently found a thinner layer of gliosis or extremely close approximation of the tumor to the vital neurons in the hypothalamus without glial cleavage.

From our pathological studies, it must be concluded that real total removal of craniopharyngiomas even using surgical microscopes is not always possible without potential neuronal damage. In addition to pathological factors, it is also known that many clinical factors influence the results of extensive surgery. Among these, the size of the tumor, the irregularity of the floor of the third ventricle, and dysfunction of the hypothalamus such as the preoperative exsistence of diabetes insipidus or psychiatric signs, are correlated with the prognosis. Regarding the size of the tumor, Katz et al. ${ }^{10}$ reported from Matson's series of radical operations ${ }^{15)}$ that large cystic tumors showed poor prognosis, which was the same as our results. It is of interest that an irregular defect in the third ventricular floor may reflect finger-shape or island-like invasion of the tumor into the hypothalamus which was shown in autopsy materials. The presence of diabetes insipidus and/or psychiatric signs before the operation are also risk factors in extensive surgery of craniopharyngiomas. Although diabetes insipidus can be successfully controlled by hormone substitution therapy, ${ }^{22)}$ psychiatric signs are still uncontrollable complications as Kahn et al. have suggested from their experience. ${ }^{9}$ The responsible site for these signs in cases of craniopharyngiomas has been attributed to the posterior location, with the involvement of mamillary bodies. Three out of five deceased cases showed psychiatric signs with involvement of the region.

\section{References}

1) Backlund, E-O.: Studies on craniopharyngiomas. III. Stereotaxic treatment with intracystic yttrium-90. Acta Chir Scand 139: 237-247, 1973.

2) Bartlett, J. R.: Craniopharyngiomas- a summary of 85 cases. $J$ Neurol Neurosurg Psychiatry 34: 37-41, 1971.

3) Bloom, H. J. G. and Harmer, C. L.: Craniopharyngiomas. Br Med J 2: 288-289, 1972.

4) Bloom, H. J. G. : Combined modality therapy for intracranial tumors. Cancer 35: 111-120, 1975.

5) Garcia-Uria, J.: Surgical experience with craniopharyngioma in adults. Surg Neurol 9: 11-14, 1978.

6) Hoff, J. T. and Patterson, R. H.: Craniopharyngiomas in children and adults. $J$ Neurosurg 36: 299-302, 1972.

7) Hoffman, H. J., Henderick, E. B., Humphreys, R. P., Buncic, J. R., Armstrong, D. L. and Jenkin, R. D. T.: Management of craniopharyngioma in children. $J$ Neurosurg 47: 218-227, 1977.

8) Kageyama, N.: Clinical problems of pituitary adenomas and craniopharyngioma. Neurol Med Chir (Part II) 16: 89-102, 1976.

9) Kahn, E. A., Gosch, H. H., Seegar, J. F. and Hicks, S. P.: Forty-five years experience with the craniopharyngiomas. Surg Neurol 1: 5-12, 1973.

10) Katz, E. L.: Late results of radical excision of craniopharyngiomas in children. $J$ Neurosurg 42: 86-90, 1975.

11) Kobayashi, T. and Kageyama, N.: Internal irradiation for cystic craniopharyngioma. Neurol Med Chir (Tokyo) 19: 421-429, 1979.

12) Kramer, S., Southhard, M. and Mansfield, C. M.: Radiotherapy in the management of craniopharyngiomas. Further experiences and late results. Am $J$ Roentgenol 103: 44-52, 1968.

13) Kubota, T., Yamamoto, S., Kohno, H., Ito, H. and Hayashi, M.: Operative procedures of craniopharyngioma estimated by autopsy findings. Neurol Med Chir (Tokyo) 20: 341354, 1980.

14) Lichter, A. S., Wara, W. M., Sheline, G. E., Townsend, J. J. and Wilson, C. B. : The treatment of craniopharyngiomas. Int $J$ Radiat Oncol Biol Phys 2: 675-683, 1977.

15) Matson, D. D. and Crigler, J. F.: Management of craniopharyngioma in childhood. $J$ Neurosurg 30: 377-390, 1969.

16) McKissock, W. and Ford, R. K.: Results of treatment of the craniopharyngiomas (abstract). J Neurol Neurosurg Psychiatry 29: 475, 1966.

17) Onoyama, Y., Ono, K., Yabumoto, E. and 
Takeuchi, J.: Radiation therapy of craniopharyngioma. Radiology 125: 799-803, 1977.

18) Petito, C. K., DeGirolami, U. and Earle, K. M.: Craniopharyngiomas. A clinical and pathological review. Cancer 37: 1944-1952, 1976.

19) Russell, D. S. and Rubinstein, L.J.: "Pathology of tumours of the Nervous System", 4th Ed., Edward Arnold Ltd., 1977, 33p.

20) Shapiro, K., Till, K. and Grant, D. N.: Craniopharyngioma in childhood. A rational approach to treatment. $J$ Neurosurg 50: 617-623,
1979.

21) Sharma, V., Tandon, P. N., Saxena, K. K., et al.: Craniopharyngiomas treated by a combination of surgery and radiotherapy. Clin Radiol 25: 13-17, 1974.

22) Shucart, W. A. and Jackson, I.: Management of diabetes insipidus in neurosurgical patients. Neurosurg 44: 65-71, 1976

23) Sweet, W. H.: Radical surgical treatment of craniopharyngioma. Clin Neurosurg 23: 5279, 1975. 